\title{
Skin permeation mechanism and bioavailability enhancement of celecoxib from transdermally applied nanoemulsion Faiyaz Shakeel*1, Sanjula Baboota ${ }^{2}$, Alka Ahuja², Javed Ali² and Sheikh Shafiq ${ }^{3}$
}

Address: ${ }^{1}$ Department of Pharmaceutics, Faculty of Pharmacy, Al-Arab Medical Sciences University, Benghazi-5341, Libya, ${ }^{2}$ Department of Pharmaceutics, Faculty of Pharmacy, Jamia Hamdard, Hamdard Nagar, New Delhi-110062, India and ${ }^{3}$ New Drug Delivery System (NDDS), Zydus Cadila Research Centre, Ahemdabad, India

Email: Faiyaz Shakeel* - faiyazs@fastmail.fm; Sanjula Baboota - sbaboota@rediffmail.com; Alka Ahuja - alkaahuja@yahoo.com; Javed Ali - javedaali@yahoo.com; Sheikh Shafiq - shafiq_sheikh@fastmail.fm

* Corresponding author

Published: 9 July 2008

Journal of Nanobiotechnology 2008, 6:8 doi:10.1186/1477-3।55-6-8
Received: 28 February 2008

Accepted: 9 July 2008

This article is available from: http://www.jnanobiotechnology.com/content/6/1/8

(c) 2008 Shakeel et al; licensee BioMed Central Ltd.

This is an Open Access article distributed under the terms of the Creative Commons Attribution License (http://creativecommons.org/licenses/by/2.0), which permits unrestricted use, distribution, and reproduction in any medium, provided the original work is properly cited.

\begin{abstract}
Background: Celecoxib, a selective cyclo-oxygenase- 2 inhibitor has been recommended orally for the treatment of arthritis and osteoarthritis. Long term oral administration of celecoxib produces serious gastrointestinal side effects. It is a highly lipophilic, poorly soluble drug with oral bioavailability of around $40 \%$ (Capsule). Therefore the aim of the present investigation was to assess the skin permeation mechanism and bioavailability of celecoxib by transdermally applied nanoemulsion formulation. Optimized oil-in-water nanoemulsion of celecoxib was prepared by the aqueous phase titration method. Skin permeation mechanism of celecoxib from nanoemulsion was evaluated by FTIR spectral analysis, DSC thermogram, activation energy measurement and histopathological examination. The optimized nanoemulsion was subjected to pharmacokinetic (bioavailability) studies on Wistar male rats.
\end{abstract}

Results: FTIR spectra and DSC thermogram of skin treated with nanoemulsion indicated that permeation occurred due to the disruption of lipid bilayers by nanoemulsion. The significant decrease in activation energy $(2.373 \mathrm{kcal} / \mathrm{mol})$ for celecoxib permeation across rat skin indicated that the stratum corneum lipid bilayers were significantly disrupted $(p<0.05)$. Photomicrograph of skin sample showed the disruption of lipid bilayers as distinct voids and empty spaces were visible in the epidermal region. The absorption of celecoxib through transdermally applied nanoemulsion and nanoemulsion gel resulted in 3.30 and 2.97 fold increase in bioavailability as compared to oral capsule formulation.

Conclusion: Results of skin permeation mechanism and pharmacokinetic studies indicated that the nanoemulsions can be successfully used as potential vehicles for enhancement of skin permeation and bioavailability of poorly soluble drugs.

\section{Background}

By many estimates up to $90 \%$ of new chemical entities (NCEs) discovered by the pharmaceutical industry today and many existing drugs are poorly soluble or lipophilic compounds [1]. The solubility issues obscuring the delivery of these new drugs also affect the delivery of many 
existing drugs (about 40\%). Relative to compounds with high solubility, poor drug solubility often manifests itself in a host of in vivo consequences like decreased bioavailability, increased chance of food effect, more frequent incomplete release from the dosage form and higher intersubject variability. Poorly soluble compounds also present many in vitro formulation development hindrances, such as severely limited choices of delivery technologies and increasingly complex dissolution testing with limited or poor correlation to the in vivo absorption. However, important advances have been made in improving the bioavailability of poorly soluble compounds, so that promising drug candidates need no longer be neglected or have their development hindered by sub optimal formulation. In addition to more conventional techniques, such as micronization, salt formation, complexation etc, novel solubility/bioavailability enhancement techniques have been developed. The recent trend for the enhancement of solubility/bioavailability is lipid based system such as microemulsions, nanoemulsions, solid dispersions, solid lipid nanoparticles and liposomes etc. This is also the most advanced approach commercially, as formulation scientists increasingly turn to a range of nanotechnology-based solutions to improve drug solubility and bioavailability.

Nanoemulsions have been reported to make the plasma concentration profiles and bioavailability of poorly soluble drugs more reproducible [1-5]. Nanoemulsions have also been reported as one of the most promising techniques for enhancement of transdermal permeation and bioavailability of poorly soluble drugs [6-12]. Nanoemulsions are thermodynamically stable transparent (translucent) dispersions of oil and water stabilized by an interfacial film of surfactant and cosurfactant molecules having a droplet size of less than $100 \mathrm{~nm}[10,11,13]$. Many formulation scientists have investigated skin permeation mechanism of many drugs using chemical enhancers [14-21] and microemulsion technique [22,23]. Best of our knowledge, skin permeation mechanism of celecoxib has not been reported using microemulsion or nanoemulsion technique although these techniques have been known to enhance skin permeation of drugs effectively [6-9]. Celecoxib (CXB), a selective cyclo-oxygenase2 (COX-2) inhibitor has been recommended orally for the treatment of arthritis and osteoarthritis [24]. Long term oral administration of CXB produces serious gastrointestinal side effects [24]. It is a highly lipophilic, poorly soluble drug with oral bioavailability of around $40 \%$ (Capsule). Therefore the aim of the present investigation was to evaluate the mechanism of skin permeation and bioavailability of CXB using nanoemulsion technique.

\section{Materials and methods Materials}

Celecoxib was a kind gift sample from Ranbaxy Research Labs (India). Propylene glycol mono caprylic ester (Sefsol 218) was a kind gift from Nikko Chemicals (Japan). Diethylene glycol monoethyl ether (Transcutol-P) was gift sample from Gattefosse (France). Glycerol triacetate (Triacetin) and acetonitrile (HPLC grade) were purchased from E-Merck (India). Cremophor-EL was purchased from Sigma Aldrich (USA). Deionized water for HPLC analysis was prepared by a Milli-Q-purification system. All other chemicals used in the study were of analytical reagent grade.

\section{Preparation of nanoemulsion}

Various nanoemulsions were prepared by aqueous phase titration method (spontaneous emulsification method). Optimized nanoemulsion formulation (C2) of CXB was prepared by dissolving $2 \% \mathrm{w} / \mathrm{w}$ of CXB in $15 \% \mathrm{w} / \mathrm{w}$ combination of Sefsol-218 and Triacetin (1:1). Then $35 \% \mathrm{w} / \mathrm{w}$ mixture of Cremophor-EL and Transcutol-P (1:1) were added slowly in oil phase. Then $50 \% \mathrm{w} / \mathrm{w}$ of distilled water was added to get the final preparation.

\section{Preparation of nanoemulsion gel}

Nanoemulsions gel (NGC2) was prepared by dispersing $1 \% \mathrm{w} / \mathrm{w}$ of Carbopol-940 in sufficient quantity of distilled water. This dispersion was kept in dark for $24 \mathrm{~h}$ for complete swelling of Carbopol-940. 2\% w/w of CXB was dissolved in $15 \% \mathrm{w} / \mathrm{w}$ mixture of Sefsol-218 and Triacetin (1:1). CXB solution was added slowly to Carbopol-940 dispersion. $0.5 \% \mathrm{w} / \mathrm{w}$ of triethanolamine (TEA) was added in this mixture to neutralize Carbopol-940. Then $35 \% \mathrm{w} / \mathrm{w}$ mixture of Cremophor-EL and Transcutol-P (1:1) were added slowly. Then remaining quantity of distilled water was added to get the final preparation $100 \%$ $\mathrm{w} / \mathrm{w}$.

The composition of nanoemulsion and nanoemulsion gel are given in Table 1.

Table I: Compositions of nanoemulsion (C2) and nanoemulsion gel (NGC2)

\begin{tabular}{lcc}
\hline Ingredients & C2 & NGC2 \\
\hline CXB $(\% \mathrm{w} / \mathrm{w})$ & 2.0 & 2.0 \\
Carbopol-940 $(\% \mathrm{w} / \mathrm{w})$ & - & 1.0 \\
Sefsol $218(\% \mathrm{w} / \mathrm{w})$ & 7.5 & 7.5 \\
Triacetin $(\% \mathrm{w} / \mathrm{w})$ & 7.5 & 7.5 \\
Cremophor-EL & 17.5 & 17.5 \\
Transcutol-P $(\% \mathrm{w} / \mathrm{w})$ & 17.5 & 17.5 \\
Triethanolamine $(\% \mathrm{w} / \mathrm{w})$ & - & 0.5 \\
Distilled water to $(\% \mathrm{w} / \mathrm{w})$ & 100.0 & 100.0 \\
\end{tabular}




\section{Droplet size analysis}

Droplet size distribution of optimized nanoemulsion was determined by photon correlation spectroscopy, using a Zetasizer $1000 \mathrm{HS}$ (Malvern Instruments, UK). Light scattering was monitored at $25^{\circ} \mathrm{C}$ at a scattering angle of $90^{\circ}$. A solid state laser diode was used as light source. The sample of optimized nanoemulsion was suitably diluted with distilled water and filtered through $0.22 \mu \mathrm{m}$ membrane filter to eliminate mutiscattering phenomena. The diluted sample was then placed in quartz couvette and subjected to droplet size analysis.

\section{Preparation of full thickness rat skin}

Approval to carry out these studies was obtained from the Animal Ethics Committee of Jamia Hamdard, New Delhi, India. Male Wistar rats were sacrificed with prolonged ether anaesthesia and the abdominal skin of each rat was excised. Hairs on the skin of animal were removed with electrical clipper, subcutaneous tissues were surgically removed and dermis side was wiped with isopropyl alcohol to remove residual adhering fat. The skin was washed with distilled water, wrapped in aluminium foil and stored in a deep freezer at $-20^{\circ} \mathrm{C}$ till further use.

\section{Preparation of epidermis and stratum corneum}

The skin was treated with $1 \mathrm{M}$ sodium bromide solution in distilled water for $4 \mathrm{~h}$ [25]. The epidermis from full thickness skin was separated using cotton swab moistened with water. Epidermal sheet was cleaned by washing with distilled water and dried under vacuum and examined for cuts or holes if any. Stratum corneum (SC) samples were prepared by floating freshly prepared epidermis membrane on $0.1 \%$ trypsin solution for $12 \mathrm{~h}$. Then SC sheets were cleaned by washing with distilled water.

\section{FTIR spectral analysis of nanoemulsion treated and untreated rat skin}

SC was cut into small circular discs. $0.9 \% \mathrm{w} / \mathrm{v}$ solution of sodium chloride was prepared and $0.01 \% \mathrm{w} / \mathrm{v}$ sodium azide was added as antibacterial and antimycotic agent. $35 \mathrm{ml}$ of $0.9 \% \mathrm{w} / \mathrm{v}$ of sodium chloride solution was placed in different conical flasks and SC of approximate $1.5 \mathrm{~cm}$ diameter was floated over it for 3 days. After 3 days of hydration, these discs were thoroughly blotted over filter paper and fourier transform infra-red (FTIR) spectra of each SC disc was recorded before nanoemulsion treatment (control) in frequency range of 400 to $4000 \mathrm{~cm}^{-1}$ (Perkin Elmer, Germany). After taking FTIR spectra, the same discs were dipped into CXB nanoemulsion formulation present in $35 \mathrm{ml}$ of methanolic phosphate buffer saline (PBS) pH 7.4 (30:70). This was kept for a period of $24 \mathrm{~h}$ (equivalent to the permeation studies) at $37 \pm 2{ }^{\circ} \mathrm{C}$. Each SC disc after treatment was washed, blotted dry, and then air dried for $2 \mathrm{~h}$. Samples were kept under vacuum in desiccators for $15 \mathrm{~min}$ to remove any traces of formula- tion completely. FTIR spectra of treated SC discs were recorded again. Each sample served as its own control.

\section{DSC studies of nanoemulsion treated and untreated rat skin}

Approximately $15 \mathrm{mg}$ of freshly prepared SC was taken and hydrated over saturated potassium sulphate solution for 3 days. Then the SC was blotted to get hydration between 20 to $25 \%$. Hydrated SC sample was dipped into nanoemulsion formulation present in $35 \mathrm{ml}$ of methanolic PBS pH 7.4 (30:70). This was kept for 24 h (equivalent to the permeation studies) at $37 \pm 2{ }^{\circ} \mathrm{C}$. After treatment, SC was removed and blotted to attain hydration of $20-25 \%$, cut ( $5 \mathrm{mg}$ ), sealed in aluminum hermatic pans and equilibrated for $1 \mathrm{~h}$ before the differential scanning calorimeter (DSC) run. Then, the SC samples were scanned on a DSC6 Differential Scanning Calorimeter (Perkin Elmer, Germany). Scanning was done at the rate of $5^{\circ} \mathrm{C} / \mathrm{min}$ over the temperature range of 30 to $200^{\circ} \mathrm{C}$ $[25,26]$.

\section{Determination of activation energy}

In vitro skin permeation study of $\mathrm{CXB}$ across rat skin was carried out at 27,37 , and $47^{\circ} \mathrm{C}$ in the methanolic PBS pH 7.4 (30:70). These studies were performed on a modified Keshary-Chien diffusion cell with an effective diffusional area of $4.76 \mathrm{~cm}^{2}$ and $35 \mathrm{ml}$ of receiver chamber capacity. In the donor compartment, $1 \mathrm{ml}$ of nanoemulsion formulation was taken (containing $20 \mathrm{mg}$ of $\mathrm{CXB}$ ). Receiver compartment was composed of the vehicle only (methanolic PBS pH 7.4). Permeability coefficients were calculated at each temperature and activation energy of CXB was then calculated from Arrhenius relationship given as follows [20,27].

$$
\begin{gathered}
\mathrm{P}=\mathrm{P}_{\mathrm{o}} \mathrm{e}^{-\mathrm{Ea} / \mathrm{RT}} \text { or } \\
\log \mathrm{P}=\mathrm{Ea} / 2.303 \mathrm{RT}+\log \mathrm{P}_{\mathrm{O}}
\end{gathered}
$$

Where, Ea is the activation energy, $\mathrm{R}$ is gas constant (1.987 $\mathrm{kcal} / \mathrm{mol}$ ), $\mathrm{T}$ is absolute temperature in $\mathrm{K}, \mathrm{P}$ is the permeability cofficient, and Po is the Arrhenius factor.

\section{Histopathological examination of skin specimens}

Abdominal skins of Wistar rats were treated with optimized CXB nanoemulsion (C2) in methanolic PBS pH 7.4. After $24 \mathrm{~h}$, rats were sacrificed and the skin samples were taken from treated and untreated (control) area. Each specimen was stored in $10 \%$ formalin solution in methanolic PBS pH 7.4. The specimens were cut into section vertically. Each section was dehydrated using ethanol, embedded in paraffin for fixing and stained with hematoxylin and eosin. These samples were then observed under light microscope (Motic, Japan) and compared with control sample. In each skin sample, three dif- 
ferent sites (epidermis, dermis and subcutaneous fat layer) were scanned and evaluated for mechanism of skin permeation enhancement. These slides were interpreted by Dr. Ashok Mukherjee, Professor, Department of Pathology, All India Institute of Medical Sciences (AIIMS), New Delhi, India.

\section{Pharmacokinetic studies}

Approval to carry out pharmacokinetic studies was obtained from the Animal Ethics Committee of Jamia Hamdard, New Delhi, India. Guidelines of ethics committee were followed for the studies. Pharmacokinetic studies were performed on optimized nanoemulsion (C2), nanoemulsion gel (NGC2) and marketed capsule. The male Wistar rats were kept under standard laboratory conditions (temperature $25 \pm 2{ }^{\circ} \mathrm{C}$ and relative humidity of 55 $\pm 5 \%$ ). The rats were kept in polypropylene cages (six per cage) with free access to standard laboratory diet (Lipton feed, Mumbai, India) and water ad libitum. About $10 \mathrm{~cm}^{2}$ of skin was shaved on the abdominal side of rats in each group except group treated with marketed capsule. They were fasted for the period of $24 \mathrm{~h}$ for observations on any unwanted effects of shaving. The dose for the rats was calculated based on the weight of the rats according to the surface area ratio [28]. The rats were divided into 3 groups $(n=6)$. Group I received C2 transdermally, group II received NGC2 transdermally and group III received marketed capsule orally. The dose of CXB in all groups was $1.78 \mathrm{mg} / \mathrm{kg}$ of body weight. The rats were anaesthetized using ether and blood samples $(0.5 \mathrm{ml})$ were withdrawn from the tail vein of rat at 0 (pre-dose), 1, 2, 3, 6, 12, 24, 36 , and $48 \mathrm{~h}$ in microcentrifuge tubes in which $8 \mathrm{mg}$ of EDTA was added as an anticoagulant. The blood collected was mixed with the EDTA properly and centrifuged at $5000 \mathrm{rpm}$ for $20 \mathrm{~min}$. The plasma was separated and stored at $-21^{\circ} \mathrm{C}$ until drug analysis was carried out using HPLC.

Plasma samples were prepared by adding $500 \mu \mathrm{l}$ of plasma, $50 \mu \mathrm{l}$ standard solution of CXB, $50 \mu \mathrm{l}$ of internal standard solution (ibuprofen), $50 \mu$ l of phosphate buffer ( $\mathrm{pH} 5 ; 0.5 \mathrm{M}$ ) and $4 \mathrm{ml}$ of chloroform in small glass tubes. The tubes were vortex for $1 \mathrm{~min}$ and centrifuged for 20 min at $5000 \mathrm{rpm}$. Upper layer was discarded and the chloroform layer was transferred to a clean test tube and evaporated to dryness at $50^{\circ} \mathrm{C}$ under the stream of nitrogen. The residue was reconstituted in $100 \mu$ l of mobile phase, mixed well and $20 \mu \mathrm{l}$ of the final clear solution was injected into the HPLC system.

CXB in plasma was quantified by the reported HPLC method with slight modifications [29]. The method was validated in our laboratory. A Shimadzu model HPLC equipped with quaternary LC-10A VP pumps, variable wavelength programmable UV/VIS detector SPD-10AVP column oven (Shimadzu), SCL 10AVP system controller (Shimadzu), Rheodyne injector fitted with a $20 \mu$ l loop and Class-VP 5.032 software was used. Analysis was performed on a $\mathrm{C}_{18}$ column $(25 \mathrm{~cm} \times 4.6 \mathrm{~mm}$ ID SUPELCO $516 \mathrm{C}_{18}$ DB $5 \mu \mathrm{m}$ RP-HPLC). The mobile phase consisted of acetonitrile:water (40:60). The mobile phase was delivered at the flow rate of $0.9 \mathrm{ml} / \mathrm{min}$. Detection was performed at $260 \mathrm{~nm}$. Injection volume was $20 \mu \mathrm{l}$. The concentration of unknown plasma samples was calculated from the calibration curve plotted between peak area ratios of CXB to IS against corresponding CXB concentrations.

\section{Pharmacokinetic and statistical analysis}

The plasma concentration of CXB at different time intervals was subjected to pharmacokinetic (PK) analysis to calculate various parameters like maximum plasma concentration $\left(\mathrm{C}_{\max }\right)$, time to reach maximum concentration $\left(\mathrm{T}_{\max }\right)$, and area under the plasma concentration-time curve $\left(\mathrm{AUC}_{0 \rightarrow \mathrm{t}}\right.$ and $\left.\mathrm{AUC}_{0 \rightarrow \omega}\right)$. The values of $\mathrm{C}_{\max }$ and $\mathrm{T}_{\max }$ were read directly from the arithmetic plot of time and plasma concentration of CXB. The AUC was calculated by using the trapezoidal method. The relative bioavailability of the CXB after the transdermal administration versus the oral administration was calculated as follows:

$$
\text { F } \%=\frac{\text { AUC sample }}{\text { AUC oral }} \cdot \frac{\text { Dose oral }}{\text { Dose sample }} \times 100
$$

The PK data between different formulations was compared for statistical significance by one-way analysis of variance (ANOVA) followed by Tukey-Kramer multiple comparisons test using GraphPad Instat software (GraphPad Software Inc., CA, USA).

\section{Results and discussion Droplet size analysis}

The mean droplet size of optimized nanoemulsion (C2) was found to be $16.41 \pm 1.72 \mathrm{~nm}$. All the droplets were found in the nanometer range which indicated the suitability of formulation for transdermal drug delivery. Polydispersity signifies the uniformity of droplet size within the formulation. The polydispersity value of the formulation C2 was very low (0.105) which indicated uniformity of droplet size within the formulation.

\section{FTIR spectral analysis of formulation treated and untreated rat skin}

FTIR spectrum of untreated SC (control) showed various peaks due to molecular vibration of proteins and lipids present in the SC (Figure 1a). The absorption bands in the wave number of 3000 to $2700 \mathrm{~cm}^{-1}$ were seen in untreated SC. These absorption bonds were due to the $\mathrm{C}-\mathrm{H}$ stretching of the alkyl groups present in both proteins and lipids (Figure 1a). The bands at $2920 \mathrm{~cm}^{-1}$ and $2850 \mathrm{~cm}^{-1}$ were 


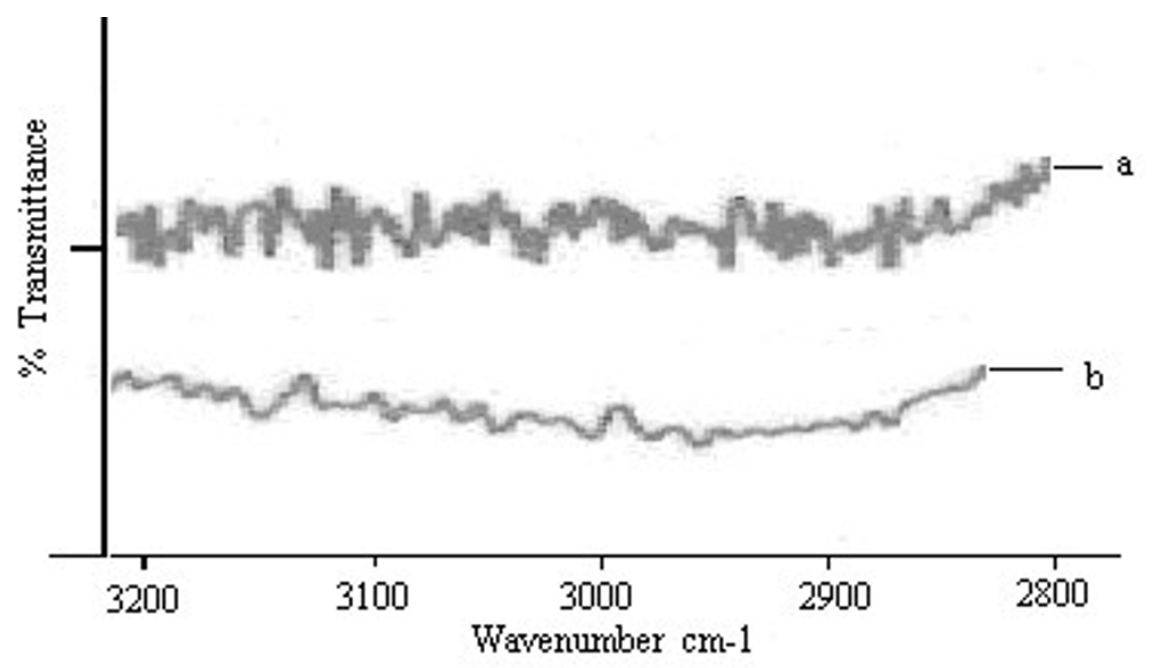

Figure I

FTIR spectra of rat SC. Change in lipid C-H stretching $\left(2920 \mathrm{~cm}^{-1}\right)$ vibrations after $24 \mathrm{hr}$ treatment with (a) control (b) C2.

due to the asymmetric $-\mathrm{CH}_{2}$ and symmetric $-\mathrm{CH}_{2}$ vibrations of long chain hydrocarbons of lipids respectively. The bands at $2955 \mathrm{~cm}^{-1}$ and $2870 \mathrm{~cm}^{-1}$ were due to the asymmetric and symmetric $\mathrm{CH}_{3}$ vibrations respectively [30]. These narrow bands were attributed to the long alkyl chains of fatty acids, ceramides and cholesterol which are the major components of the SC lipids.

The two strong bands $\left(1650 \mathrm{~cm}^{-1}\right.$ and $\left.1550 \mathrm{~cm}^{-1}\right)$ were due to the amide I and amide II stretching vibrations of SC proteins (Figure 2a). The amide I and amide II bands arisen from $\mathrm{C}=\mathrm{O}$ stretching vibration and $\mathrm{C}-\mathrm{N}$ bending vibration respectively. The amide I band consisting of components bands, represented various secondary structure of keratin.

There was clear difference in the FTIR spectra of untreated and nanoemulsion treated SC with prominent decrease in asymmetric and symmetric $\mathrm{CH}$ - stretching of peak height and area (Figure 1b).

The rate limiting step for transdermal drug delivery is lipophilic part of SC in which lipids (ceramides) are tightly packed as bilayers due to the high degree of hydrogen bonding. The amide I group of ceramide is hydrogen bonded to amide II group of another ceramide and forming a tight network of hydrogen bonding at the head of ceramides. This hydrogen bonding makes stability and strength to lipid bilayers and thus imparts barrier property to SC [31]. When skin was treated with nanoemulsion formulation (C2), ceramides got loosened because of competitive hydrogen bonding leading to breaking of hydrogen bond networks at the head of ceramides due to penetration of nanoemulsion into the lipid bilayers of SC. The tight hydrogen bonding between ceramides caused split in the peak at $1650 \mathrm{~cm}^{-1}$ (amide I) as shown in the control skin spectrum (Fig 2a). Treatment with nanoemulsion resulted in either double or single peak at 1650 $\mathrm{cm}^{-1}$ (Figure 2b) which suggested breaking of hydrogen bonds by nanoemulsion.

\section{DSC studies}

DSC thermogram of untreated rat epidermis revealed 4 endotherms (Figure 3a). The first 3 endotherms were recorded at $34^{\circ} \mathrm{C}\left(\mathrm{T}_{1}\right), 82^{\circ} \mathrm{C}(\mathrm{C} 2)$ and $105^{\circ} \mathrm{C}\left(\mathrm{T}_{3}\right)$ respectively, whereas fourth endotherm $\left(\mathrm{T}_{4}\right)$ produced a very sharp and prominent peak at $114^{\circ} \mathrm{C}$ which is attributed to SC proteins. The first endotherm (having the lowest enthalpy) was attributed to sebaceous section [32] and to minor structural rearrangement of lipid bilayer [33]. The second and third endotherm ( $\mathrm{T} 2$ and $\mathrm{T}_{3}$ ) appeared due to the melting of SC lipids and the fourth endotherm $\left(\mathrm{T}_{4}\right)$ has been assigned to intracellular keratin denaturation [14]. It was observed that both $\mathrm{T} 2$ and $\mathrm{T}_{3}$ endotherms were completely disappeared or shifted to lower melting points in thermograms of SC treated with nanoemulsion formulation (C2). This indicated that the components (oil, surfactant or cosurfactant) of nanoemulsion enhanced skin permeation of CXB through disruption of lipid bilayers. Nanoemulsion formulation (C2) also decreased the protein endotherm $\mathrm{T}_{4}$ to lower melting point, suggesting keratin denaturation and possible intracellular permeation mechanism in addition to the disruption of lipid bilayers (Figure 3b). Thus it was concluded that the intracellular transport is a possible mechanism of permeation enhancement of CXB. Another observation was that 


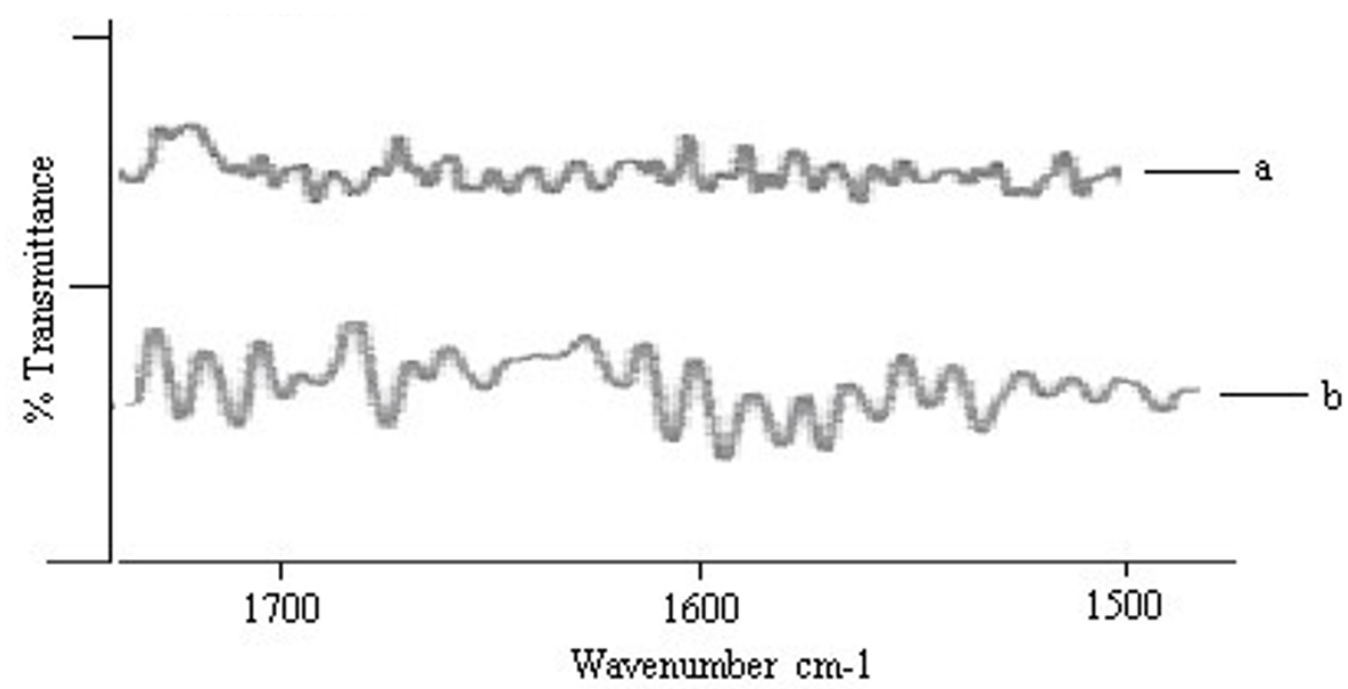

Figure 2

FTIR spectra of rat SC. Change in amide I $\left(1640 \mathrm{~cm}^{-1}\right)$ and amide II $\left(1550 \mathrm{~cm}^{-1}\right)$ stretching vibrations after $24 \mathrm{~h}$ treatment with (a) control (b) C2.

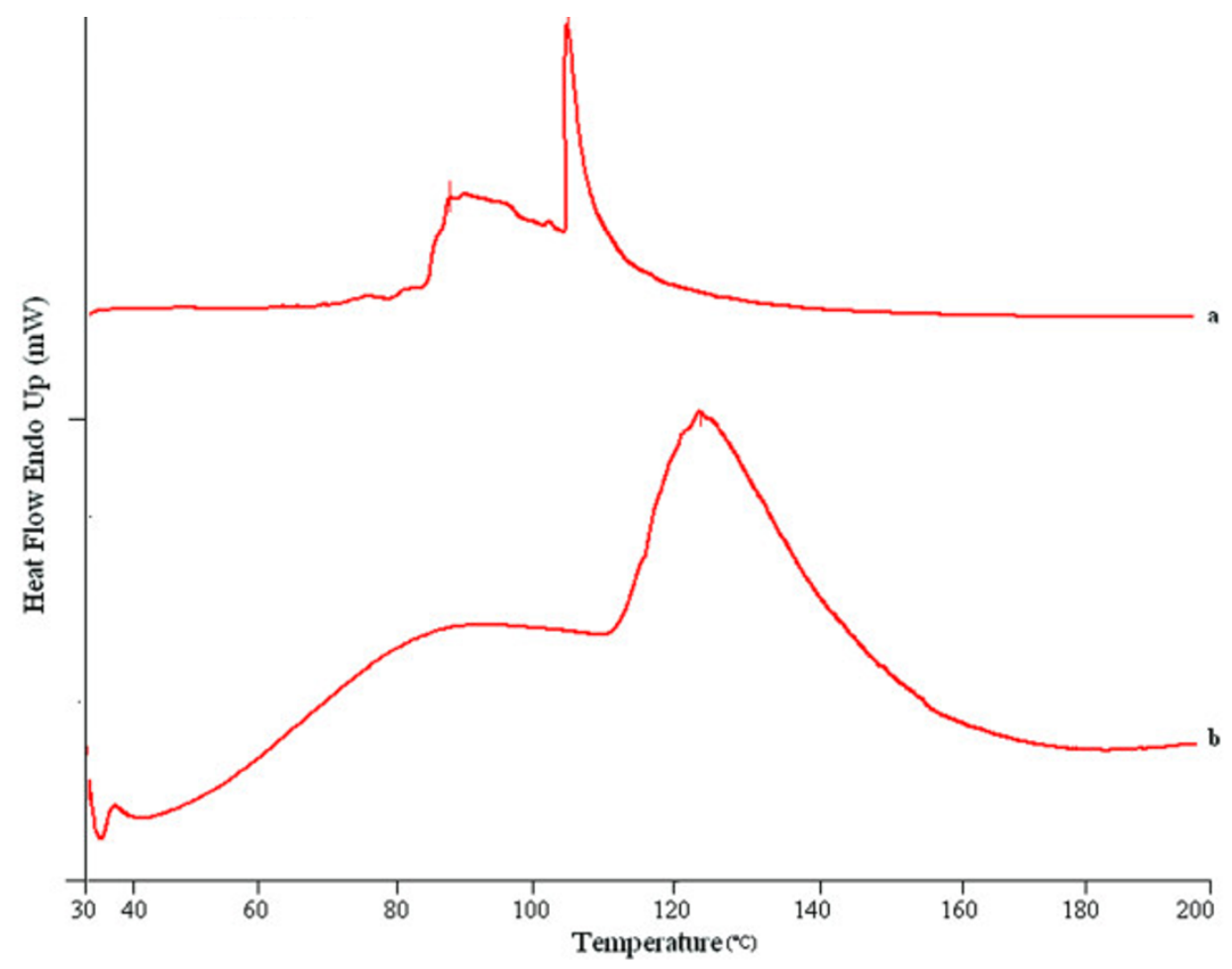

Figure 3

DSC thermogram of control SC and nanoemulsion treated SC for 24 h. (a) control (b) C2. 
$\mathrm{T}_{4}$ increased up to $122^{\circ} \mathrm{C}$ in case of nanoemulsion formulation with broadening of the peak. Shift to higher transition temperature $\left(T_{m}\right)$ and peak broadening has been attributed to dehydration of SC as another mechanism of permeation enhancement in addition to disruption of lipid resulting in higher permeation of CXB [18].

\section{Determination of activation energy}

The activation energy $\left(\mathrm{E}_{\mathrm{a}}\right)$ for diffusion of a drug molecule across skin (rat or human) depends on its route of diffusion and physicochemical properties. Nanoemulsions can change this value of $\mathrm{E}_{\mathrm{a}}$ to greater extent by their action on SC lipids. The activation energy for ion transport has been reported as 4.1 and $10.7 \mathrm{kcal} / \mathrm{mol}$ across human epidermis [34] and phosphatidylcholine bilayers respectively [35]. The Arrhenius plot between logarithms of permeability coefficient $\left(\log \mathrm{P}_{\mathrm{b}}\right)$ and reciprocal of absolute temperature $(1 / \mathrm{T})$ was found to be linear in the selected temperature range between $27-47^{\circ} \mathrm{C}$, indicating no significant structural or phase transition changes within the skin membrane (Figure 4). The value of $\mathrm{E}_{\mathrm{a}}$ for permeation of $\mathrm{CXB}$ across rat skin was calculated from the slope of Arrhenius plot. The $\mathrm{E}_{\mathrm{a}}$ of CXB from nanoemulsion formulation $\mathrm{C} 2$ was found to be $2.373 \mathrm{kcal} / \mathrm{mol}$. The significant decrease in $\mathrm{E}_{\mathrm{a}}$ for $\mathrm{CXB}$ permeation across rat skin indicated that the SC lipid bilayers were significantly disrupted $(\mathrm{p}<0.05)$.

It is also well established that ion transport across skin occurs mainly via aqueous shunt pathways [36]. In the light of these reports it can be anticipated that if a molecule moves via polar pathways across human cadaver epi- dermis then $\mathrm{E}_{\mathrm{a}}$ value would be akin to that of ion transport across skin. In our study, $\mathrm{E}_{\mathrm{a}}$ of CXB from formulation C2 was $2.373 \mathrm{kcal} / \mathrm{mol}$. Therefore it was concluded that nanoemulsions create pathways in the lipid bilayers of SC resulting in enhanced transdermal permeation of CXB [37].

\section{Histopathological studies}

The photomicrographs of control (untreated skin) showed normal skin with well defined epidermal and dermal layers. Keratin layer was well formed and lied just adjacent to the topmost layer of the epidermis. Dermis was devoid of any inflammatory cells. Skin appendages were within normal limits (Figure 5a\&b). When the skin was treated with nanoemulsion formulation (C2) for 24 $h$, significant changes were observed in the skin morphology. Low power photomicrograph of skin sample showed epidermis with a prominent keratin layer, a normal dermis and subcutaneous tissues. High power photomicrograph of skin sample showed a thickened and reduplicated stratum corneum with up to 8 distinct layers. The epidermis showed increase in its cellular layers to 46 cells. Dermis does not show any edema or inflammatory cell infiltration. The disruption of lipid bilayers was clearly evident as distinct voids and empty spaces were visible in the epidermal region (Figure 6a\&b). These observations support the in vitro skin permeation data of $\mathrm{CXB}$ (unpublished data).

There were no apparent signs of skin irritation (erythma and edema etc.) observed on visual examination of skin specimens treated with nanoemulsion formulation.

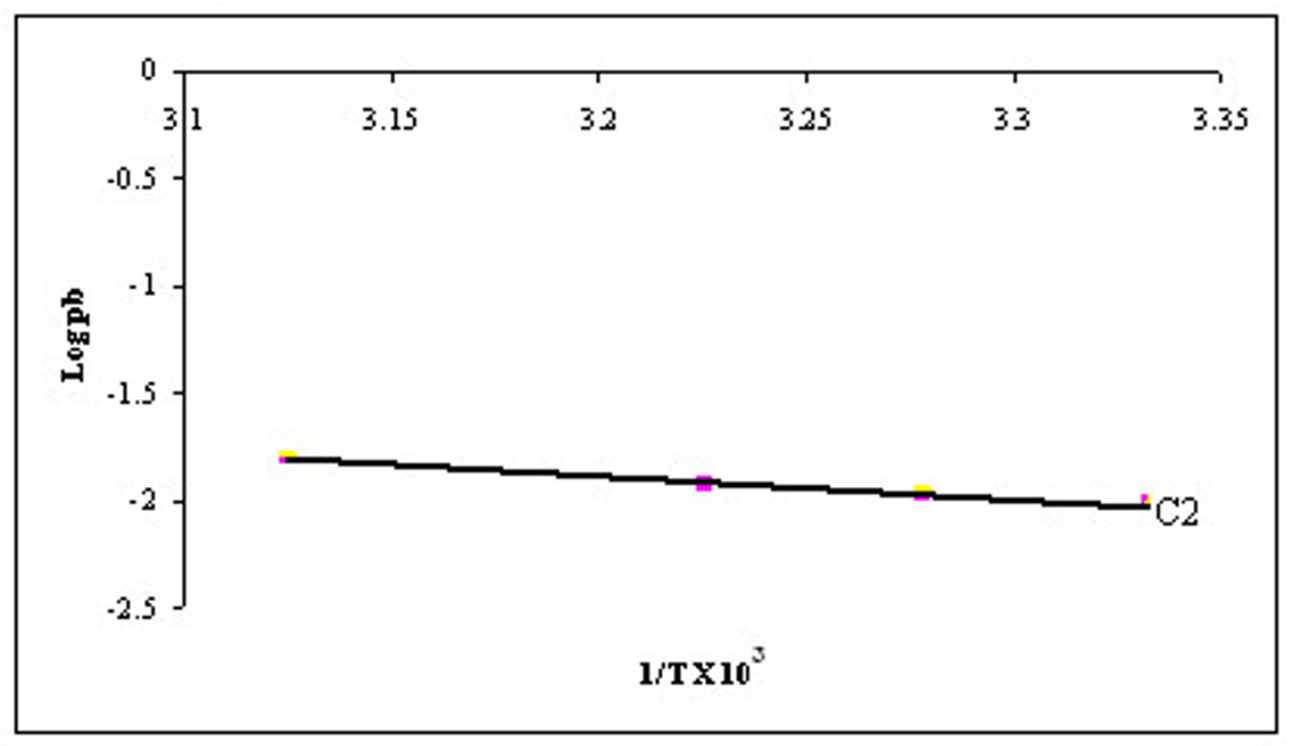

Figure 4

Arrhenius plots of $C 2$ permeation across rat skin. 

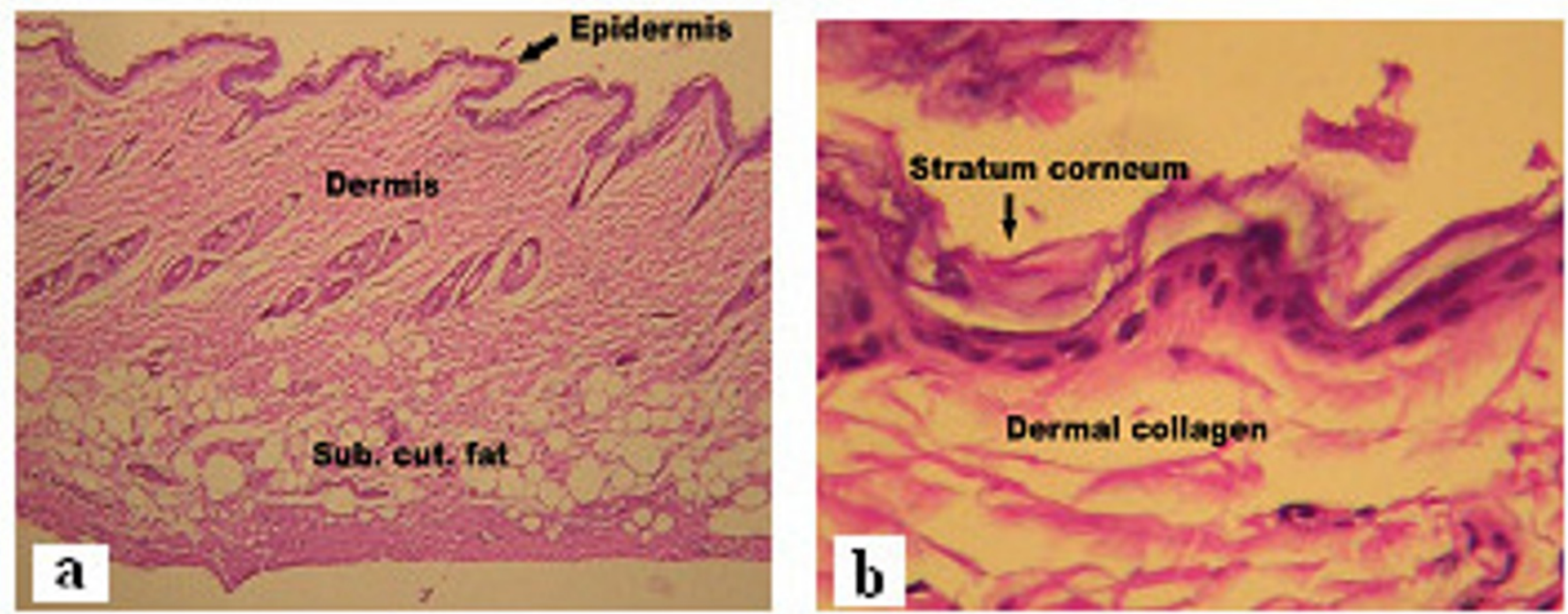

\section{Figure 5}

Photomicrographs of skin sample from control group animal showing normal epidermis, dermis and subcutaneous tissues at (a) low power view $(\mathrm{HE} \times 100)(\mathrm{b})$ high power view $(\mathrm{HE} \times 400)$.

\section{Pharmacokinetic studies}

Plasma concentration of CXB from formulations $\mathrm{C} 2$, NGC2 and capsule at different time intervals was determined by reported HPLC method. The graph between plasma concentration and time was plotted for each formulation (Fig 7). It was seen from Figure 7 that the plasma concentration profile of CXB for C2 and NGC2 showed greater improvement of drug absorption than the oral capsule formulation. Peak (maximum) plasma concentration $\left(\mathrm{C}_{\max }\right)$ of $\mathrm{CXB}$ in $\mathrm{C} 2, \mathrm{NGC} 2$ and capsule was
$680 \pm 100,610 \pm 148$ and $690 \pm 180 \mathrm{ng} / \mathrm{ml}$ respectively whereas time $\left(\mathrm{t}_{\max }\right)$ to reach $\mathrm{C}_{\max }$ was $12 \pm 2.1,12 \pm 2.4$ and $3 \pm 0.8 \mathrm{~h}$ respectively (Table $2 \&$ Figure 7 ). AUC $\mathrm{AUt}_{0 \rightarrow \mathrm{t}}$ and $\mathrm{AUC}_{0 \rightarrow \omega}$ in formulations C2, NGC2 and capsule were $14435 \pm 1741,13005 \pm 1502$ and $4366 \pm 1015 \mathrm{ng} / \mathrm{ml} . \mathrm{h}$ respectively and $19711.3 \pm 2012,17507.3 \pm 1654$ and $4688.5 \pm 1293 \mathrm{ng} / \mathrm{ml}$.h respectively (Table 2 ). These pharmacokinetic parameters obtained with formulations C2 and NGC2 were significantly different from those obtained with oral capsule formulation $(\mathrm{p}<0.05)$. The
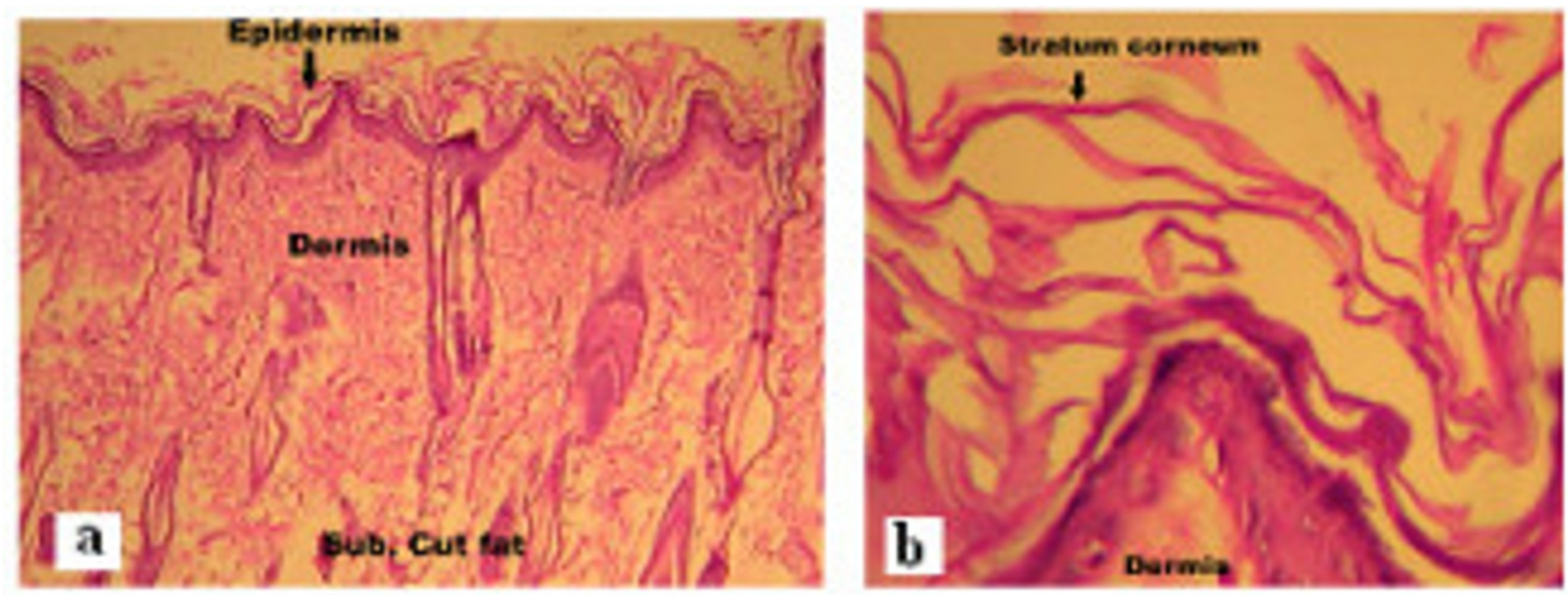

\section{Figure 6}

Photomicrographs of skin sample from nanoemulsion treated animal at (a) low power view (HE $\times 100)(b)$ high power view $(\mathrm{HE} \times 400)$. 


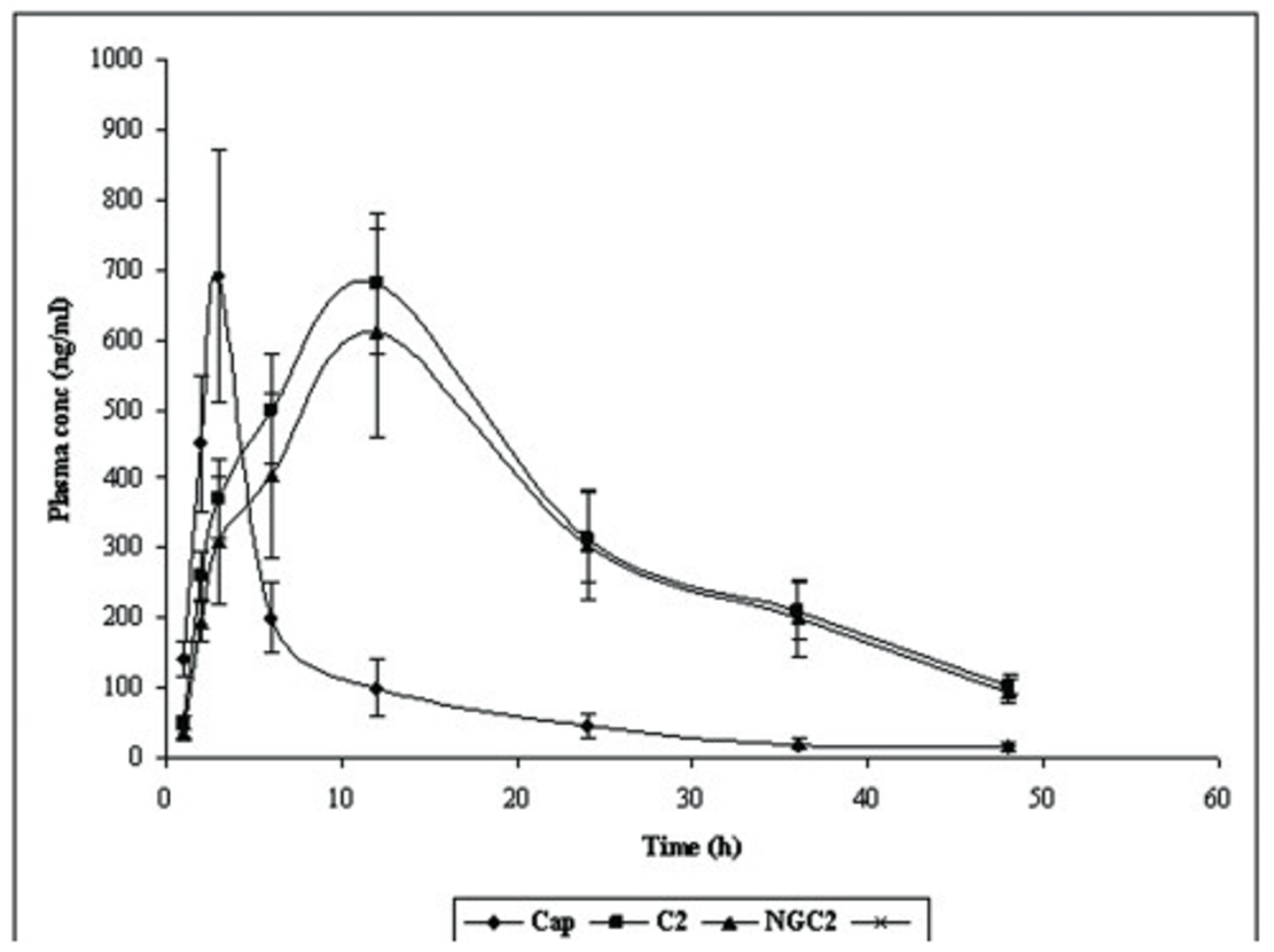

Figure 7

Plasma concentration (Mean $\pm S D$ ) time profile curve of CXB from C2, NGC2 and capsule $(n=6)$.

significant AUC values observed with C2 and NGC2 also indicated increased bioavailability of the CXB from C2 and NGC2 in comparison with oral capsule formulation $(\mathrm{p}<0.05)$. The formulations $\mathrm{C} 2$ and NGC2 were found to enhance the bioavailability of CXB by 3.30 and 2.97 folds (percent relative bioavailability 330 and 297) with reference to the oral capsule (Table 2). This increased bioavailability from transdermal formulations (C2 and NGC2) may be due to the enhanced skin permeation and avoidance of hepatic first pass metabolism.

\section{Conclusion}

FTIR spectra and DSC thermogram of skin treated with nanoemulsion indicated that permeation occurred due to the extraction of SC lipids by nanoemulsion. The signifi- cant decrease in activation energy for CXB permeation across rat skin indicates that the SC lipid bilayers were significantly disrupted $(\mathrm{p}<0.05)$. Photomicrograph of skin sample showed the disruption and extraction of lipid bilayers as distinct voids and empty spaces were visible in the epidermal region. There were no apparent signs of skin irritation observed on visual examination of skin specimens treated with nanoemulsion formulation. The pharmacokinetic studies revealed significantly greater extent of absorption than the oral capsule formulation ( $\mathrm{p}$ $<0.05$ ). The absorption of CXB from C2 and NGC2 resulted in 3.30 and 2.97 fold increases in bioavailability as compared to the oral capsule formulation. Results of these studies indicate that nanoemulsions can be success-

Table 2: Pharmacokinetic parameters (Mean \pm SD, $n=6$ ) of CXB from C2, NGC2 and capsule

\begin{tabular}{|c|c|c|c|c|}
\hline Formulation & $\begin{array}{l}t_{\max }{ }^{a} \pm S D \\
\text { (h) }\end{array}$ & $\begin{array}{l}C_{\max } b^{b} \pm S D \\
(\mathrm{ng} / \mathrm{ml})\end{array}$ & $\begin{array}{l}\operatorname{AUC}_{0 \rightarrow \mathrm{t}}{ }^{\mathrm{C}} \pm \mathrm{SD} \\
(\mathrm{ng} / \mathrm{ml} . \mathrm{h})\end{array}$ & $\begin{array}{l}\operatorname{AUC}_{0 \rightarrow \alpha}{ }^{d} \pm S D \\
(\mathrm{ng} / \mathrm{ml} . \mathrm{h})\end{array}$ \\
\hline $\mathrm{C} 2$ & $12 \pm 1.8$ & $680 \pm 100$ & $|4435 \pm 174|$ & $19711.3 \pm 2012$ \\
\hline NGC2 & $12 \pm 2.0$ & $610 \pm 148$ & $13005 \pm 1502$ & $17507.3 \pm 1654$ \\
\hline Capsule & $3 \pm 0.8$ & $690 \pm 180$ & $4366 \pm 1015$ & $4688.5 \pm 1293$ \\
\hline
\end{tabular}

a time of peak concentration; b peak of maximum concentration; c area under the concentration time profile curve until last observation; ${ }^{d}$ area under curve extrapolated to infinity 
fully used for enhancement of skin permeation as well as bioavailability of poorly soluble drugs.

\section{Abbreviations}

FTIR: Fourier transforms infra-red; DSC: Differential scanning calorimetry; CXB: Celecoxib; SC: Stratum corneum; $\mathrm{C}_{\text {max: }}$ Peak or maximum plasma concentration; $\mathrm{T}_{\max }$ Time to reach peak plasma concentration; AUC: Area under plasma concentration time profile curve; NCEs: New chemical entities; COX-2: Cyclo-oxygenase-2; HPLC: High performance liquid chromatography; C2: Optimized nanoemulsion; NGC2: Nanoemulsion gel; PBS: Phosphate buffer saline; AIIMS: All india institute of medical sciences; EDTA: Ethylene diamine tetra-acectic acid; rpm: Revolution per minute; min: Minutes; IS: Internal standard; RP-HPLC: Reverse phase high performance liquid chromatography; PK: Pharmacokinetic; $\mathrm{AUC}_{0 \rightarrow \mathrm{t}}$ Area under curve from time o to $\mathrm{t} ; \mathrm{AUC}_{0 \rightarrow \omega}$ : Area under curve from time o to infinitive; \% F: Percent relative bioavailability; ANOVA: Analysis of variance.

\section{Competing interests}

The authors declare that they have no competing interests.

\section{Authors' contributions}

FS performed pharmacokinetic studies. SB and AA prepared skin for Histopathological examination and activation energy measurement. JA took FTIR spectra and DSC thermogram. SS validated HPLC method for analysis of drug in plasma samples. SB, AA and JA guided the studies. Finally manuscript has been checked and approved by all the authors.

\section{Acknowledgements}

The authors are thankful to Dr. Ashok Mukherjee, for observation and interpretation of photomicrographs of skin samples. The authors are also thankful to Nikko Chemicals (Japan) and Gattefosse (France) for gift samples of Sefsol 218 and Transcutol-P respectively.

\section{References}

I. Kommuru TRK, Gurley B, Khan MA, Reddy IK: Selfemulsifying drug delivery systems (SEDDS) of coenzyme Q I0: Formulation development and bioavailability assessment. Int J Pharm 200I, 2 I 2:233-246.

2. Constantinides PP: Lipid microemulsions for improving drug dissolution and oral absorption and biopharmaceutical aspects. Pharm Res 1995, 12:1561-1572.

3. Lawrence MJ, Rees GD: Microemulsion-based media as novel drug delivery systems. Adv Drug Deliv Rev 2000, 45:89-I2I.

4. Kawakami K, Yoshikawa T, Moroto Y, Kanaoka E, Takahashi K, Nishihara $Y$, Masuda $K$ : Microemulsion formulation for enhanced absorption of poorly soluble drugs I.Prescription design. J Control Rel 2002, 81 :65-74.

5. Kawakami K, Yoshikawa T, Moroto Y, Kanaoka E, Takahashi K, Nishihara $\mathrm{Y}$, Masuda K: Microemulsion formulation for enhanced absorption of poorly soluble drugs II. In vivo study. J Control Rel 2002, $81: 75-82$

6. Baboota S, Alazaki A, Kohli K, Ali J, Dixit N, Shakeel F: Development and evaluation of a microemulsion formulation for transdermal delivery of terbenafine. PDA J Pharm Sci Technol 2007, 6 I (4):276-285.
7. Baboota S, Shakeel F, Ahuja A, Ali J, Shafiq S: Design development and evaluation of novel nanoemulsions formulations for transdermal potential of celecoxib. Acta Pharm 2007, 8:3 I 6-332.

8. Shakeel F, Baboota S, Ahuja A, Ali J, Aqil M, Shafiq S: Nanoemulsions as vehicles for transdermal delivery of aceclofenac. AAPS Pharm Sci Tech 2007, 8:EI04.

9. Shakeel F, Baboota S, Ahuja A, Shafiq S, Faisal S, Ali J: Enhanced transdermal delivery of aceclofenac using nanoemulsion technique. J Pharm Pharmacol 2007, 93(Suppl I):3I-37.

10. Shafiq S, Shakeel F, Talegaonkar S, Ahmad FJ, Khar RK, Ali M: Design and development of oral oil in water ramipril nanoemulsion formulation: In vitro and in vivo assessment. J Biomed Nanotech 2007, 3:28-44.

II. Shafiq S, Shakeel F, Talegaonkar S, Ahmad FJ, Khar RK, Ali M: Development and bioavailability assessment of ramipril nanoemulsion formulation. Eur J Pharm Biopharm 2007, 66:227-242.

12. Karande $P$, Jain A, Mitragotri S: Development of high through screening platforms for discovery of novel transdermal permeation enhancers. Nat Biotech 2004, 22:192-197.

13. Shafiq S, Shakeel F, Talegaonkar S, Ali J, Baboota S, Ahuja A, Khar RK, Ali M: Formulation development and optimization using nanoemulsion technique: a technical note. AAPS Pharm Sci Tech 2007, 8:E28.

14. Goodman M, Barry BW: Action of penetration enhancers on human stratum corneum as assessed by differential scanning calorimetry. In Percutaneous absorption 2nd edition. Edited by: Bronaugh RL, Maibach HI. Marcel Dekker: New York and Basel; 1989:567-595.

15. Yamane MA, Williams AC, Barry BW: Terpenes penetration enhancers in propylene glycol/water co-solvent systems: Effectiveness and mechanism of action. J Pharm Pharmacol 1995, 47:978-989.

16. Zhao K, Singh J: Mechanisms of percutaneous absorption of tamoxifen by terpenes: eugenol, D-limonene and menthone. J Control Release 1998, 55(2-3):253-264.

17. Stott PW, Williams AC, Barry BW: Mechanistic study into the enhanced transdermal permeation of a model $\beta$-blocker, propranolol, by fatty acids: a melting point depression effect. Int J Pharm 2001, 219:161-176.

18. Vaddi HK, Ho PC, Chan SY: Terpenes in propylene glycol as skin-penetration enhancers: permeation and partition of haloperidol, fourier transform infrared spectroscopy and differential scanning calorimetry. J Pharm Sci 2002, 9I:1639-165I.

19. Cotte M, Dumas P, Besnard M, Tchoreloff P, Walter P: Synchrotron FT-IR microscopic study of chemical enhancers in transdermal drug delivery: example of fatty acids. J Control Rel 2004, 97:269-281.

20. Narishetty STK, Panchagnula R: Transdermal delivery of zidovudine: effect of terpenes and their mechanism of action. J Control Rel 2004, 95:367-379.

21. Cole L, Heard C: Skin permeation enhancement potential of aloe vera and a proposed mechanism of action based upon size exclusion and pull effect. Int J Pharm 2007, 333:10-16.

22. Changez M, Varshney M, Chander J, Dinda AK: Effect of the composition of lecithin/n-propanol/isopropyl myristate/water microemulsions on barrier properties of mice skin for transdermal permeation of tetracaine hydrochloride: In vitro. Coll Surf B: Biointerf 2006, 50: 18-25.

23. Dreher F, Walde R, Walther R, Wehrli E: Interaction of a lecithin microemulsion gel with human stratum corneum and its effect on transdermal transport. J Control Rel I997, 45: | |3|-I40.

24. Gaurel A, Martel AM, Castaner J: Celecoxib, anti-inflammatory, cyclo-oxygenase-2 inhibitor. Drugs Future 1997, 22:71 I-7I 4.

25. Panchagnula R, Salve PS, Thomas NS, Jain AK, Ramarao P: Transdermal delivery of naloxone: effect of water, propylene glycol, ethanol and their binary combinations on permeation through rat skin. Int J Pharm 200I, 21 9:95-105.

26. Cumming $\mathrm{KI}$, Winfield AJ: In vitro evaluation of a series of sodium carboxylates as dermal penetration enhancers. Int J Pharm 1994, 108:|4|-|48.

27. Golden GM, Guzek DB, Harris RR, McKie JE, Potts RO: Lipid thermotropic transition in human stratum corneum. J Invest Dermatol 1986, 86:255-259.

28. Ghosh MN: Fundamentals of Experimental Pharmacology Hilton and company: Kolkata; 2005: 192. 
29. Jalalizadeh H, Amini M, Ziace V, Farsam SA, Shafice A: Determination of celecoxib in human plasma by high-performance liquid chromatography. J Pharm Biomed Anal 2004, 35:665-670.

30. Babua RJ, Pandit JK: Effect of penetration enhancers on the release and skin permeation of bupranolol from reservoirtype transdermal delivery systems. Int J Pharm 2005, 288:325-334.

3I. Panchagnula R, Bokalial R, Sharma P, Khandavilli S: Transdermal delivery of naloxone: skin permeation, pharmacokinetic, irritancy and stability studies. Int J Pharm 2005, 293:2 13-223.

32. Lee PJ, Langer R, Shastri VP: Role of n-methyl pyrrolidone in the enhancement of aqueous phase transdermal transport. J Pharm Sci 2005, 94:912-917.

33. Xiong GL, Quan D, Maibach HI: Effects of penetration enhacers on in vitro percutaneous absorption of low molecular weight heparin through human skin. J Control Rel 1996, 42:289-296.

34. Pagano R, Thompson TE: Spherical bilayer membranes: electrical and isotopic studies of ion permeability. J Mol Biol 1968, 38:4I-57.

35. Monti D, Saettone MF, Giannaccini B, Galli-Angeli D: Enhancement of transdermal penetration of dapiprazole through hairless mouse skin. J Control Rel 1995, 33:71-77.

36. Cullander PA, Guy RH: Sites of iontophoretic current flow into the skin: identification and characterization with the vibrating probe electrode. J Invest Dermatol 199I, 97:55-64.

37. Clarys P, Alewaeters K, Jadoul A, Barel A, Manadas RO, Préat V: In vitro percutaneous penetration through hairless rat skin: influence of temperature, vehicle and penetration enhancers. Eur J Pharm Biopharm 1998, 46:279-283.

Publish with Biomed Central and every scientist can read your work free of charge

"BioMed Central will be the most significant development for disseminating the results of biomedical research in our lifetime. "

Sir Paul Nurse, Cancer Research UK

Your research papers will be:

- available free of charge to the entire biomedical community

- peer reviewed and published immediately upon acceptance

- cited in PubMed and archived on PubMed Central

- yours - you keep the copyright

Submit your manuscript here:

http://www.biomedcentral.com/info/publishing_adv.asp
BioMedcentral 